\title{
Contexto Multicódigos e o Design
}

Francisco José Paoliello Pimenta 1

\begin{abstract}
ResumO: Esta comunicação pretende contribuir para o debate sobre fundamentação teórica com base semiótica para produções na área do Design. Neste sentido, argumenta que o atual ambiente sígnico, marcado pelas relações multicódigos e pela emergência da hipermídia, se mostra mais favorável à aplicação da Semiótica de Peirce, sustentada na lógica da natureza, em relação às correntes derivadas da lingüística e, portanto, da lógica do verbal.
\end{abstract}

\section{Palavras-chave: semiótica; ambiente multicódigos; design.}

\begin{abstract}
This paper aims to contribute to the debate about semiotic as an analytical base for Design area productions. It argues that Peirce's semiotic deals better with the context that characterizes present sign processes, its multicode relationships and the emergence of hypermedia, than the linguistic approaches, established upon verbal logic.
\end{abstract}

Key words: semiotics; multicode context; design

\section{desafio das linguagens eletrônicas}

Doutor em Comunicação e Semiótica (PUC/SP - TSOA/NYU) - Professor Adjunto III (FACOM/UFJF) -
São inumeráveis os aspectos relevantes do campo de aproximação entre a Semiótica e o Design. Entre eles, destaca-se a existência de duas vertentes de estudos de linguagem bastante distintas e, daí, a discussão sobre suas respectivas adequações ao atual ambiente, marcado pela hibridização de códigos e pela emergência da hipermídia digital. Antes de tudo, é preciso ressaltar que onde existe troca de informação, de qualquer tipo, aí se encontram, também, as questões semióticas, uma vez que, nestas trocas, é imprescindível a intermediação sígnica. E quando a própria linguagem é o objeto de nossas reflexões, como acontece na esfera do Design, a relevância dos princípios semióticos é ainda mais ressaltada.

A partir deste recorte, argumenta-se, em primeiro lugar, que o evento mais significativo na esfera da Semiótica, no século $X X$, foi o surgimento de produções de linguagem com características diferentes da linguagem verbal, 
escrita e falada. Os primeiros suportes aptos ao desenvolvimento destes outros tipos de linguagem foram o cinema e o rádio, seguidos pela televisão. A partir dos anos 50, a criação do transístor, dos circuitos integrados e, mais tarde, dos chips provocaram a miniaturização e a popularização dos mais diversos equipamentos eletrônicos, entre eles os computadores.

O desenvolvimento tecnológico da eletrônica prosseguiu até que, na segunda metade da década de 60 , as produções sígnicas nestes suportes tornaram-se um grande desafio para o paradigma lingüístico, devido à disseminação das produções não-lineares e, portanto, sem a sintaxe das línguas. Contribuiu para este processo a intensa semiotização do ambiente urbano, marcado não apenas pelas intervenções da arquitetura, mas também por variados processos sígnicos voltados para a propaganda e a informação.

Até então, o verbal havia mantido sua hegemonia como linguagem de maior prestígio, e, muito sugestivamente, a matriz saussureana permanecia na fronteira das ciências da linguagem, principalmente com o Estruturalismo. Na produção e análise de linguagem, fosse ela literária, dos jornais e revistas, da arte e do design, do cinema, do rádio ou da televisão, o modelo básico a ser levado em conta era o da matriz saussureana, ou seja, o das línguas.

A influência de Ferdinand de Saussure decorre de seus cursos de lingüistica ministrados em Genebra, em 1907, 1908/9 e 1910/11. Como Saussure não deixou um livro acabado, os editores da primeira edição, de 1915, do "Curso de Lingüística Geral” foram obrigados a recorrer às anotações de alunos, combinadas com manuscritos esparsos (Saussure, 1972: 2).

Saussure se apoiou em Guilherme de Ockham, na escola de Port Royal, do século XVII, e no conceptualismo de Locke. De Ockham veio a idéia de que signos substituiriam o objeto externo, além da importância conferida ao pensamento, pelo destaque ao signo lingüístico mental, considerado "natural". Como os gramáticos de Port Royal, viu a linguagem como reflexo do pensamento, cujas leis seriam iguais para todos. Construções sígnicas guardariam uma similaridade com a estrutura profunda do real e expressariam o significado de forma comum a todas as línguas. A similaridade entre real e linguagem obedeceria a um esquema cartesiano a priori, conduzindo a padrões de comportamento lingüístico. Contudo, a influência mais forte vem do empirismo de Locke, que estabeleceu as bases da lingüística moderna ao defender a arbitrariedade entre palavras e coisas, e deslocou o eixo das relações de similaridade do contexto da mente humana para o âmbito da cultura.

Segundo Paul Ricoeur, os princípios filosóficos de Saussure seriam:

"1. A idéia de que a linguagem ou língua consiste num sistema de diferenças sem termos absolutos. A única realidade da linguagem seria aquilo que separa os fonemas ou lexemas, sem qualquer substância física ou mental; 2. O código que governa os diversos sistemas lingüísticos não são derivados dos sujeitos que deles fazem uso, ou dos atos individuais da fala, mas são inconscientes e categóricos, criando espaço para a estruturação das comunidades lingüísticas; 3 . O próprio signo, que Saussure considera a entidade fundamental da linguagem, também consiste numa diferença em si mesmo, entre significante e significado."

Prossegue Ricoeur: "Esta diferença é interna ao signo e, por esta razão, vem de dentro do universo do discurso; o signo não requer relacionamentos 'externos', tais como aquele entre o signum (signo) e a res (coisa) no qual Santo Agostinho baseou sua teoria da linguagem. Assim, para o filósofo educado em lingüística estrutural, a linguagem é um sistema sem 'termos', um sistema sem 'sujeitos', e um sistema sem 'coisas" (Ricoeur, 1979: 261). Portanto, segundo 
Saussure, o signo lingüístico é uma entidade psíquica, que relaciona conceito (o significado) e 'imagem acústica' (o significante), e não uma coisa e um nome. Esta visão valorizava o aspecto conceitual em detrimento de uma lógica de relações externa à cognição, conforme defenderia o realismo de Peirce.

Da matriz saussureana vieram o Círculo Lingüístico de Praga, a Escola de Copenhague, com destaque para Hjelmslev, e o núcleo norte-americano de Sapir e Bloomfield. Jakobson e Martinet aprofundaram a vertente por meio da lingüística funcional, que abriu caminho para a lingüística estrutural. Também Noam Chomsky, na criação de sua gramática transformacional, buscou em Saussure pontos em comum com as teses de Port Royal, principalmente a idéia de padrões lingüísticos invariantes. $O$ formalismo russo, de Moscou e Petrogrado, se apoiou nos trabalhos de Saussure, a partir de Potiebniá e Viesselóvsky, e os desenvolveu ao estabelecer ligações com teóricos da lingüística estrutural (Schnaiderman, 1979).

É interessante observar este alcance da matriz saussureana relacionado ao contexto social do hemisfério ocidental no início do século $X X$, e ao desenvolvimento tecnológico, artístico e dos meios de comunicação. Neste período, o universo mecânico, característico da segunda Revolução Industrial, havia trazido consigo um apelo ao racionalismo, ao nacionalismo e ao antropocentrismo, que se disseminaram pelas mais variadas esferas. Era, então, de fato, um momento propício para tais teses conceptualistas.

O desenvolvimento mais importante dessa matriz foi o Estruturalismo, que chegou a ser quase uma unanimidade nos estudos de linguagem até o final da década de 60, época em que Jakobson afirmaria num congresso, em Bucareste:

\footnotetext{
“A propósito, aludo deliberadamente à 'análise estrutural', porquanto, quaisquer que sejam as dissensões sectárias entre os lingüistas contemporâneos e suas divergências em terminologia, técnica e interesses principais, a análise das estruturas lingüísticas é o denominador comum de todas as correntes científicas contemporâneas, algo que distingue incisivamente a pesquisa das últimas quatro ou cinco décadas dos principais caminhos e objetivos da lingüística no começo do século vinte e fim do dezenove" (Jakobson, 1970: 26).
}

O Estruturalismo está ligado a Lévi-Strauss, considerado seu criador, a partir da etno-lingüística; a Jacques Lacan, teórico de extração freudiana, que defendeu um ordenamento psíquico inconsciente independente do sujeito; a Michel Foucault, que propôs a idéia de teorias do conhecimento sem encadeamento desde a Renascença, as quais governariam sub-sistemas estruturados de forma subconsciente e não-reflexiva; e a Louis Althusser, segundo o qual o marxismo seria uma ciência de estruturas, forças e modelos, sem consciência, subjetividade ou pensamento. Foi a base de escolas como a gramatologia, de Jacques Derrida; a semanálise, de Julia Kristeva; a translingüística de Barthes e a Semiótica soviética de lúri Lotman.

O Estruturalismo está relacionado ao conceptualismo e à filosofia da semelhança, ao defender a estrutura como particularidade auto-suficiente, que prescinde de elementos externos para que seja inteligível. Sobre esta base, outras marcas são: a estrutura é um sistema em transformação; é independente de formalizações por parte dos teóricos; constitui uma totalidade que define seus elementos e é auto-regulável (Piaget, 1968: 13). Como podemos observar, esta é a própria caracterização da língua, de acordo com a matriz saussureana.

O conceito de estrutura, assim como o de língua para Saussure, não envolve a noção de substância, pois é um sistema sem sujeitos.Paul Ricoeur sublinha esta auto-limitação: 
"Enquanto as escolas filosóficas inspiradas pelo evolucionismo sustentam as idéias de gênese, desenvolvimento e derivação histórica como essenciais para a inteligibilidade da realidade humana, por outro lado a compreensão histórica se torna suspeita, e mesmo problemática, para a inteligência estrutural, para a qual os padrões 'sincrônicos' são os mais facilmente inteligíveis. A história da cultura parece muito mais uma sucessão de configurações epistemológicas, cada uma tendo a coerência de uma epistémé poderosamente estruturada, embora as transições entre elas permaneçam contingentes e consequentemente não inteligíveis em sua maior parte”(Ricoeur, 1979: 263).

Uma das principais tendências da Semiologia derivadas da lingüística com influência sobre produtores contemporâneos, seja na literatura, na comunicação, na arte e no design, é o desconstrucionismo, inspirado pelos 'textualistas' reunidos pela revista Tel Quel, de Paris, formado, dentre outros, por Barthes, Todorov, Sollers e Julia Kristeva. (Ong, 1982: 165 - 170). Para os desconstrucionistas, a escrita tem uma particularidade independente da língua falada, e poderia ser considerada uma criação tecnológica de um determinado período histórico, com impactos específicos sobre o pensamento humano a partir da época em que foi interiorizada.

O grande espaço para a liberdade expressiva é a escrita e não a fala, diz Derrida, pois tem uma anterioridade em relação aos demais códigos, ao compartilhar qualidades com conceitos distantes da razão, como o corpo, a vida e o insconciente. Tal desconstrução da razão e do fonocentrismo resgataria a escrita, um rizoma gerador de sentidos submerso por séculos de "injusta valorização" da voz, e denunciaria o poder inserido na cadeia sintagmática, tomada como mais natural. Além do movimento lateral das diferenças ("différence"), existiria na escrita o abismo da contínua prorrogação dos significados ("différance"). O movimento dos sentidos seria, assim, não somente marcado pelos vestígios, rastros ou traços ("trace") dos demais signos compartilhados na escrita, como também pela dinâmica gerada pelas infinitas referências intemporais a um outro lugar, que é a própria ausência.

Tal noção de amplitude, de espaço combinatório, ligado à vida e ao inconsciente, por sua vez, é devedora da formulação da ausência realizada pelos Estruturalistas, sobre a base principal de Heidegger. De acordo com Derrida, a linguagem é uma estrutura que não é aquela do mundo externo à mente, e, portanto, não tem compromissos com determinada significação. Se todas as implicações de um poema forem examinadas, por exemplo, será observado que o poema não é completamente consistente consigo mesmo (Ong, 1990, pp.166-169).

\section{A opção da semiótica realista}

A instituição da língua ou da escrita como modelo pode ser considerada, contudo, o calcanhar de Aquiles da Semiótica derivada da lingüística. E foi a partir desta alegada fragilidade que uma Semiótica realista começou a ser construída, a partir do final da década de 60, inclusive no Brasil. Em 1968, Haroldo de Campos criticava a idéia de Barthes de que a semiologia seria apenas uma parte da lingüística, e destacava a proposta de Jakobson de uma 'pansemiótica':

"A língua é apenas um dos sistemas de signos e a lingüística tão-somente uma das províncias da Semiótica. Esta é a colocação que nos parece mais fecunda e aberta. Realmente, a adoção da linguagem verbal como padrão absoluto e tirânico 
de todos os demais sistemas de signos, a redução destes à condição de sistemas heterônomos, pode levar a descaminhos perigosos e empobrecedores. Lévi-Strauss, por exemplo, que em matéria de arte tem concepções bastante tradicionais, recusa o nome de linguagem aos sistemas de signos que não apresentam a dupla articulação existente na linguagem verbal”.(Campos, 1969: 131)

O semioticista norte-americano Joseph Ransdell considerou este fato um “imperialismo lingüístico”:

\begin{abstract}
"Um modelo convencionalista, estabelecido originalmente somente com o significado lingüístico em mente, é estendido para cobrir todos e quaisquer fenômenos sígnicos. Tudo o que tem caráter semiótico é para ser compreendido em termos de regras e códigos, tudo é uma expressão de uma língua ou algo logicamente semelhante a uma língua, e o significado de tudo é arbitrário, no mesmo sentido no qual a língua é arbitrária. A Semiótica continental chamada 'semiologia' ilustra isto muito bem em seu movimento da lingüística saussureana às análises Estruturalistas da literatura, moda, música, mito e assim por diante. Em nosso país (EUA), o movimento foi retardado devido à relativamente atrasada aparição da lingüística chomskyana, que é a sua base natural na lingüística AngloAmericana."(Ransdell, 1979: 280)
\end{abstract}

Tais posturas críticas foram, então, buscar na Semiótica de Charles Peirce uma fundamentação mais adequada à posição que defendiam. De fato, a Semiótica peirceana aparecia como instrumento ideal para a análise dos novos produtos dos meios visuais e sonoros, devido à sua sustentação filosófica e não meramente lingüística. Mais do que isso, em vista de suas bases realistas, ou seja, por considerar o real independente da cognição humana, esta Semiótica parecia mais apta a lidar com os novos fenômenos, não sistematizados ainda por nenhuma cultura e, portanto, além dos referenciais do conceptualismo verbalista.

Assim, em substituição à lógica mental da língua, adotou-se o argumento de Peirce de que qualquer tipo de linguagem, humana ou não, deriva da lógica da natureza, na qual a própria existência de vida implica em processos semióticos. Para Peirce, na natureza, e, por extensão, na linguagem, ocorreriam dois tipos de generalidade ou Universais: a generalidade do que não é completamente determinado ou individual, a Primeiridade, e a generalidade das proposições e leis, ou Terceiridade. Entre estas esferas estaria a categoria da Secundidade, ou seja, aquela que compreende o universo das ações e reações, no âmbito do existente. A articulação das categorias é a chave para a compreensão da Semiótica de Peirce.

Entretanto, a aplicação desta Semiótica na produção e na análise sígnicas enfrenta sérios obstáculos, em relação ao que ocorreu com o Estruturalismo. Este, dependendo de sua ciência de fundo, fosse ela a psicologia, a etnografia, o marxismo ou a crítica feminista, tinha um caminho conhecido no momento de sua aplicação, isto é, a estrutura da língua. Mais tarde, o pós-estruturalismo aprofundou este processo de análise, sob a influência de filósofos como Heidegger e Deleuze, mas, nem por isso abandonou sua referência ao paradigma lingüístico.

Já a Semiótica de Peirce, ao introduzir a categoria da Primeiridade, relacionada ao caos e à indeterminação, abriu, já de início, um amplo campo de investigação e análise, porém impossível de ser esquematizado, o que a afasta de muitos teóricos e produtores. Suas outras complexidades, que, na verdade, decorrem dos próprios processos que visa analisar, a tornam também um instrumental difícil de ser repassado na esfera acadêmica. Contudo, a hibridização de imagens, textos e sons com a tatilidade obtida nos novos 
suportes, em interação com o ambiente urbano, impregnado de signos, dão origem a processos de linguagem com características muito mais amplas do que o verbal e este é um desafio que deve ser enfrentado.

\section{Uma semiótica para o contexto multicódigos}

'De fato, o contexto atual das diversas produções de linguagem, entre elas a esfera das artes e do design, é marcado pelo caráter multicódigos e pela emergência da hipermídia (Cotton,1997:56-7). Assim, tendo em vista a articulação de suportes e códigos, desde o planejamento gráfico, incluindo a tipologia, até os textos, animações, vídeos e sons, entre eles a voz, abre-se, cada vez mais, a possibilidade das produções sígnicas recuperarem diferentes aspectos da realidade de forma rica e sofisticada. Tendo em vista que a Semiótica realista é baseada na lógica da natureza e não do verbal, é possível, já de início, por meio da categoria da Primeiridade, a análise das qualidades dos eventos, ou seja, de processos que envolvem similaridades ou compartilhamento de características entre o signo e o objeto, às vezes numa escala tal que, num primeiro momento, possam parecer indistinguíveis.

Tal similaridade nos conduziria ao objeto, via signo, de uma forma próxima daquela que ocorre sem a intermediação dos sistemas técnicos, reproduzindo nossa sinestesia cotidiana com o real. A Semiótica de Peirce aparece, assim, como instrumental útil na análise e no suporte para até para a produção de fenômenos deste tipo, como acontece ultimamente nas artes plásticas, onde aumenta a produção de ambientes voltados para a interação dos usuários com as obras, isto é, as instalações, muitas vezes sustentadas na hipermídia. Estes são processos complexos de qualificação do signo em relação a sistemas codificados, como o verbal, que apenas oferece ao usuário adjetivos, ou termos que funcionam como tal, a serem adaptados a todas as situações, inusitadas ou não. E se os processos sígnicos não mais se detêm no verbal, como utilizá-lo como base de análise, como propõe a Semiologia lingüística?

Com a Semiótica realista é possível, ainda, compreender que não só existem relações de qualidades entre signo e objeto, de caráter autônomo em relação ao que pensam seus produtores, como há também imposições de características do objeto. Segundo Peirce, esta seria a esfera das relações icônicas, ainda hoje mal compreendidas e aplicadas genericamente a tudo que implique referência a imagens. Bem compreendido, contudo, este conceito nos revela um variado campo de articulações sígnicas que só não é levado em consideração, na maioria das vezes, por absoluta falta de meios para enxergá-lo.

Outro aspecto importante refere-se ao fato de que o atual ambiente hipermídia amplia as possibilidades de representação dos sujeitos, por estar mais apto a descrever as complexidades de relações nas quais eles estão imersos. Nestes casos, suas próprias criações sígnicas entram em jogo, ampliando em muito o conceito de sujeito. Ao reproduzir interações entre usuários de sistemas interligados, a hipermídia faz com que todos se tornem produtores em potencial de signos compartilhados, restringindo a imposição de classificações arbitrárias.

Há também uma ampliação do conceito de objeto, que decorre, por sua vez, de uma visão mais abrangente do conceito de real, proposta pela Semiótica realista. Segundo Peirce, nem a cognição ou qualquer investigação 
científica definiriam o que é o real, visto como externo ao pensamento humano, embora seja por ele apreensível, em certa medida.

Estes são apenas algumas das múltiplas considerações relativas às relações signo/objeto que poderíamos destacar, no atual contexto multicódigos. Outros aspectos poderiam ser ressaltados, entre eles aqueles que ocorrem na esfera do Interpretante (Pimenta, 1993: pp.75-80; 1998: pp.85-109; 1999A: pp.62-9; 1999B: pp.77-90; 1999C: pp.67-77; $2001 \mathrm{~A}:$ CD; 2001 B: CD; 2002: CD). Além disso, a própria questão, mais específica, da fundamentação teórica fornecida pela Semiótica e sua relação com o Design é igualmente rica e complexa, porém espero ter deixado um pouco mais claro, aqui, o fato de que tal aproximação não só é possível como extremamente desejável.

COTTON, Bob \& Oliver, R. Understanding Hypermidia 2.000. London: Phaidon, 1997.

BOLER, JOHN F. Charles Peirce and Scholastic Realism: A Study of Peirce's Relation to John Duns Scotus. Seattle. University of Washington Press, 1963.

CAMPOS, Haroldo de. A Arte no Horizonte do Provável. São Paulo. Perspectiva, 1969.

DERRIDA, Jacques. Gramatologia. SP: Perspectiva, 1973. A Escritura e a Diferença. SP: Perspectiva, 1995. Espectros de Marx. Rio: Relume-Dumará, 1994.

ECO, Umberto. A Estrutura Ausente. SP: Perspectiva, 1997.

JAKOBSON, Roman. Lingüística, Poética, Cinema. São Paulo. Perspectiva, 1970. 1985. Diálogos - Roman Jakobson \& Krystyna Pomorska. SP. Cultrix,

LEPSCHY, Giulio C. A Lingüística Estrutural. São Paulo. Perspectiva, 1975. LYOTARD, Jean-François. La Condition Post-Moderne. Paris. Les Ed. de Minuit, 1979.

MICHAEL, Fred. "Two Forms of Scholastic Realism in Peirce's Philosophy" in Transactions of the Charles Sanders Society, Vol. XXIV no. 3. Amherst, University of Massachusetts Press, 1988.

ONG, Walter J. Orality and Literacy. London. Routledge., 1982

PEIRCE, Charles Sanders. Collected Papers. 8 vols. Cambridge. Harvard University Press, 1931-1958.

Semiótica e Filosofia. Tradução de Octanny Mota e Leonidas Hegenberg. São Paulo. Cultrix, 1972.

Semiótica. Tradução de Teixeira Coelho. SP. Perspectiva, 1977.

Press, 1982.

Writings of Charles S. Peirce. Bloomington. Indiana University 
Escritos Coligidos. Tradução de Armando D’Oliveira e Sérgio

Pomerangblum in Os Pensadores. 3a. edição. São Paulo. Abril Cultural, 1983.

PIAGET, Jean. Le Structuralisme. Paris. P.U.F, 1968.

PIMENTA, Francisco J. P. "Tecnologia Eletrônica e Jornalismo" in São Paulo em Perspectiva. Vol 7 no. 4. pp 75-80. SP. Fundação SEADE, 1993.

"Duas Tendências em Semiótica" in Lumina. Vol 1. no. 1. pp. 85-110. Juiz de Fora: Editora da UFJF, 1998.

"Intersemiose e Multimídia" in Ícone. Vol 1. no. 4. pp. 63-70. Recife: Universitária da UFPE, 1999A.

"Novo Conservadorismo e Ambiente Hipermídia" in Fronteiras estudos midiáticos. Vol 1. no. 1. São Leopoldo: Ed. da UNISINOS, 1999B.

"Webdesign e Informação" in Lumina. Vol 2. no. 2. pp.67-78. Juiz de Fora: Editora da UFJF, 1999C.

"Desafios para a Esquerda no Ciberespaço" in Anais do V Congresso de Ciências, Humanas, Letras e Artes das IFES/MG. Ouro Preto: Ed. da UFOP, $2001 \mathrm{~A}$.

"Pensar Globalmente e Agir Localmente: contribuiçōes da Semiótica de Peirce" in Anais do V Cong. Bras. de Semiótica. SP: Ed. Fac. Belas Artes, 2001 B. "Produçōes Multicódigos e o Conceito de Signo Genuíno em Peirce" in Anais do XXV Congresso da INTERCOM. Salvador: Ed. da UFBA, 2002.

RANSDELL, Joseph "Semiotic Objectivity" in Semiotica, 26 3/4. Mouton. La Haye, 1979.

RICOEUR, Paul. Main Trends in Philosophy. New York. Holmes \& Meyer, 1979.

SAUSSURE, Ferdinand de. Curso de Lingüistica Geral. São Paulo. Cultrix, 1972.

SCHNAIDERMAN, Boris. Semiótica Russa. São Paulo. Perspectiva, 1979. 